\title{
The full spectrum of ethical issues in dementia care: systematic qualitative review
}

\author{
Daniel Strech, Marcel Mertz, Hannes Knüppel, Gerald Neitzke and Martina Schmidhuber
}

\section{Background}

Integrating ethical issues in dementia-specific training material, clinical guidelines and national strategy plans requires an unbiased awareness of all the relevant ethical issues.

\section{Aims \\ To determine systematically and transparently the full spectrum of ethical issues in clinical dementia care.}

\section{Method}

We conducted a systematic review in Medline (restricted to English and German literature published between 2000 and 2011) and Google books (with no restrictions). We applied qualitative text analysis and normative analysis to categorise the spectrum of ethical issues in clinical dementia care.

\section{Results}

The literature review retrieved 92 references that together mentioned a spectrum of 56 ethical issues in clinical dementia care. The spectrum was structured into seven major categories that consist of first- and second-order categories for ethical issues.

\section{Conclusions}

The systematically derived spectrum of ethical issues in clinical dementia care presented in this paper can be used as training material for healthcare professionals, students and the public for raising awareness and understanding of the complexity of ethical issues in dementia care. It can also be used to identify ethical issues that should be addressed in dementia-specific training programmes, national strategy plans and clinical practice guidelines. Further research should evaluate whether this new genre of systematic reviews can be applied to the identification of ethical issues in other cognitive and somatic diseases. Also, the practical challenges in addressing ethical issues in training material, guidelines and policies need to be evaluated.

\section{Declaration of interest}

None.
Clinical practice guidelines, national strategy plans (such as the French Alzheimer plan), the World Alzheimer Reports, and many scientific and non-scientific publications all stress the existence of various ethical issues in dementia care and the importance of awareness and capacity building in this area. ${ }^{1,2}$ A core challenge for the adequate development of reports, guidelines and training programmes that address ethical issues in dementia care is an unbiased and comprehensive account of all (discussed/reported) ethical issues at stake. Such an unbiased and comprehensive set of ethical issues (a full spectrum of ethical issues) in dementia care can be based on a systematic literature review. This review serves several purposes. First, it raises awareness of the variety of ethical issues and the complexity of ethical conduct in dementia care. Second, together with a comprehensive list of the underlying publications, it can be used to build the basis for the systematic development of information and training materials for health professionals, relatives, patients or society as a whole. Finally, it can be used as the basis for a rational and fair selection of all those ethical issues that should be addressed (with more or less priority) in health policy decision-making and national or local dementia strategies, position papers or clinical practice guidelines.

There are several recent books, reports and review papers intended to highlight (implicitly or explicitly) the range of ethical issues in dementia care. ${ }^{3-6}$ To date, the British Nuffield Council on Bioethics report Dementia: Ethical Issues is probably the most extensive. ${ }^{2}$ Its development involved a working group of 14 experts (mostly from the UK), public consultations, fact-finding meetings and peer review. However, the report, as well as most other existing overviews, could be classified as a narrative (non-systematic) review that did not employ explicit measures to prevent bias and to guarantee comprehensiveness in identifying and presenting relevant literature. Also, the Nuffield Council report is, understandably, oriented specially to the situation in the UK. Furthermore, because of their narrative approach, the mentioned reviews are not structured in a way that clearly illustrates the full spectrum of ethical issues in dementia care. To our knowledge there is only one review of all ethical issues in dementia that employed a systematic review methodology. ${ }^{7}$ This review focused on the older literature published between 1980 and 2000 and presented ethical issues in only one small-scale table listing 20 broad categories (for example advance directives, decision-making or feeding issues) and some examples of subcategories (such as living wills, euthanasia, genetics). This review did not include any further explanation of ethical issues in dementia care, nor link the set of ethical issues to the retrieved references. Another systematic review focused more specifically on empirical literature studying ethical issues in dementia from the perspective of non-professional carers. ${ }^{8}$

The purpose of our review was to determine the full spectrum of ethical issues in clinical dementia care based on a systematic review of the recent literature published between 2001 and 2011 (including journal articles, reports and books). We define a 'full spectrum of disease-specific ethical issues (DSEIs)' as a structured, qualitative account of ethical issues in the context of a specific disease (such as dementia), divided into broad categories and narrow subcategories that are based on text examples from the original literature that was included in the review. The purpose of our review is purely descriptive ('empirical' in its literal meaning). A description of the full spectrum of DSEIs prepares the ground for the planning and development of clinical guidelines, national and local dementia strategies and curricula for teaching and capacity-building activities. The aim of our review, therefore, was not to make judgements on the practical relevance or value of specific ethical issues. Moreover, this review does not present any normative recommendations on how to deal with every single ethical issue detected. In the discussion section, however, we highlight core methodological steps that should be 
taken into account when drafting normative recommendations on the basis of the results of the review.

\section{Method}

\section{Literature search and eligibility criteria}

We searched in Medline using the following search algorithm: $(((($ "Ethics"[Mesh])) OR ("ethics"[ti])) OR ("ethical"[ti])) AND $(((($ "Dementia"[Mesh])) OR ("Dementia"[ti])) OR ("Alzheimer's Disease"[ti])) OR ("Alzheimer Disease"[ti])). The search was restricted to English and German language literature and to publications from 1 January 2000 to 31 January 2011. We searched in Google books with the search string "Dementia AND ethics". Because of the vast number of hits (12 200) and because Google books listed 'most relevant' hits at the top of the list, we focused on the first 100 . The ordering for relevance had face validity as we found, among these first 100 hits, many textbooks and monographs that dealt with dementia and ethics we were aware of. No search restrictions were used for the Google books search. The Discussion explains and justifies why we restricted our literature search to Medline and Google books.

For the definition of DSEI we referred to the ethical theory of principlism ${ }^{9}$ that forms the basis of many ethical and medical professionalism frameworks. ${ }^{10,11}$ Principlism is based on the four principles of beneficence, non-maleficence, respect for autonomy and justice. These principles represent prima facie binding moral norms that must be followed unless they conflict, in a particular case, with an equal or greater obligation. Moreover, they provide only general ethical orientations that require further detail to give guidance in concrete cases. Thus, when being applied, the principles have to be specified and - if they conflict - balanced against one another. With respect to the principlism approach, a DSEI might arise (a) because of the inadequate consideration of one or more (specified) ethical principles (for example: insufficient consideration of patient preferences in dementia care decisions) or (b) because of conflicts between two or more (specified) ethical principles (for example, balancing the benefits, harms and the respect of patient autonomy in decision-making for or against physical restraints on account of inappropriate patient behaviour).

We included a publication only if: (a) it described a DSEI in clinical dementia care, and (b) the DSEI can be dealt with by individual caregivers or care institutions and does not depend on preceding health policy or political decision-making (for example campaigns for reducing the stigma of dementia, political decisions about the limitations of voting by people with dementia), and (c) it does not relate only to ethical issues in research on dementia (research ethics), and (d) the publication was a peer-reviewed article, a scientific book (for example textbooks or monographs) or a national-level report.

\section{Extraction and categorisation of DSEIs}

Our aim was to develop a qualitative framework of narrow and broad categories of DSEIs (the full spectrum of DSEIs) that best accommodated the DSEI mentioned in the included publications. We identified and compared paragraphs that mentioned DSEIs across papers. We matched discussion of DSEIs from one paper with DSEIs from another. We then built first-order (broad) and second-order (narrow) categories for DSEIs that captured similar DSEIs mentioned in different papers.

Paragraphs from the retrieved literature were extracted that described situations that explicitly or implicitly relate to our definition of DSEI. Extraction and categorising of DSEIs unavoidably involves interpretative tasks (for example which text passages deal with a DSEI? What is the appropriate broad and narrow category for the DSEI?). To uphold the validity of coding as well as intercoder reliability we employed the following procedure. Three authors (D.S., M.M. and M.S.) identified and initially categorised DSEIs independently in a subsample of five publications that all could be classified as narrative reviews. ${ }^{3-6,12}$ The authors discussed whether paragraphs mentioned a DSEI and how they should be categorised. The remaining 87 publications were grouped in three clusters of 47, 20 and 20 publications. All publications that at initial inspection appeared to be more detailed and comprehensive were purposively put together in the first cluster of 47 publications. One author (M.S.), with a $\mathrm{PhD}$ in philosophy, then extracted and categorised DSEIs from this first cluster. The result was a first version of the DSEI spectrum. The second and third clusters were then used to check theoretical saturation of the DSEI spectrum. Theoretical saturation implies that no new categories can be generated. ${ }^{13}$ The other authors (D.S., M.M., G.N. and H.K.) with professional backgrounds in clinical psychiatry, clinical ethics consultation, philosophy and health services research checked the extraction and categorisation of DSEI in a random sample of 18 publications. Coding problems were resolved by frequent meetings and discussions with all authors. Because the aim of our review was not to assess how often a certain DSEI was mentioned in the literature we only extracted two paragraphs with similar content for each DSEI. We extracted more than two paragraphs per DSEI only in those cases where the content allowed further specification of a certain DSEI.

\section{Results}

Our literature search retrieved 559 references of which 92 were finally included in the review (Fig. 1). More than half (47, 51\%) were published between January 2008 and February 2011. Twothirds were peer-reviewed journal articles $(62,67 \%)$ published in 42 different journals including all relevant disciplines (Table 1). Other publication sources were for example book chapters, monographs or reports. Most journal articles and all but one book were written in English (78, 85\%).

The 92 publications together included a spectrum of 56 DSEIs that were grouped under seven major categories: diagnosis and indication; patient decision-making competence; disclosure and patient information; decision-making and informed consent; social and context-related aspects; professional conduct and evaluation; and specific care situations (see Appendix). For each major category, DSEIs were further specified in first- and second-order DSEI categories (Appendix). For example, the major category 'Diagnosis and medical indication' consists of 12 second-order DSEIs grouped under 4 first-order DSEIs. An example of a first-order DSEI is 'Adequate point of making a diagnosis'. This DSEI consists of three second-order DSEIs, of which one is 'Risk of disavowing signs of illness and disregarding advance planning. A text example (among others) that built the basis for this DSEI is the following: 'But there is also the opposite risk that out of a laudable wish to preserve a person's freedom and to avoid giving false label to an existential problem, signs of illness are missed and the ill old person is denied necessary and effective treatment.' ${ }^{3}$ We found text passages in other references that allowed further specification of this second-order DSEI. We cite these references in the Appendix, but for didactic and readability purposes we did not further specify third- and fourth-order DSEIs in this paper. Our analysis received theoretical saturation for the first- and second-order DSEI categories after analysing the third cluster of retrieved references (see Method). Online Table DS1 presents one or two text examples for each of the 56 DSEIs. We 


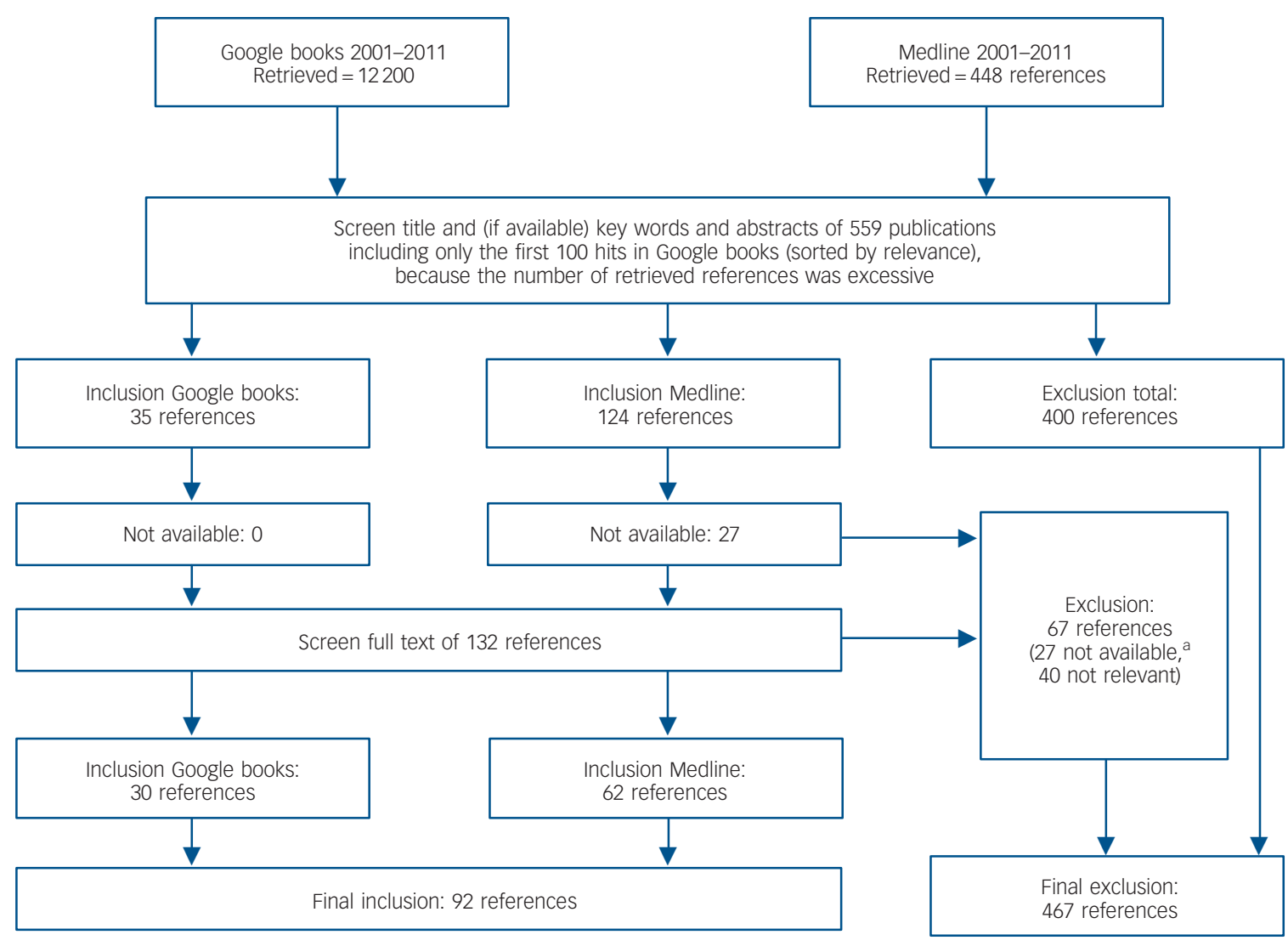

Fig. 1 Flow chart for inclusion/exclusion of references.

therefore have not repeated the presentation of DSEI categories and the underlying text examples in the results section.

The first six main categories involve DSEIs that deal with specific steps in the circular processes of medical decision-making (diagnosis, patient information, treatment/care decisions, evaluation of decisions, etc.) that are characteristic of the management of all diseases but are considered with respect only to dementia in this paper. The seventh major category involves DSEIs that deal with specific situations in the management of dementia that in principle involve all steps of the decision-making process (for example dealing with tube feeding, restraints or suicidality).

\section{Table 1 Characteristics of included publications}

References, $n$ (journals, $n$ )

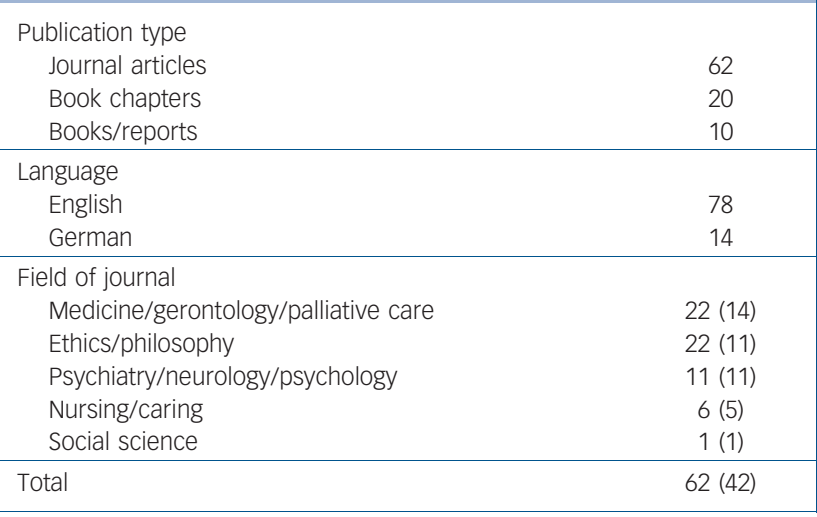

\section{Discussion}

Dementia care in all its interactions and care situations is deeply intertwined with ethical issues. Dealing with ethical issues in a systematic and transparent manner requires, first of all, an unbiased awareness of the spectrum and complexity of DSEIs. Second, it seems important for didactic and pragmatic purposes to fit this spectrum of DSEIs to everyday care situations and to the stepwise processes of medical decision-making rather than to more abstract philosophical categories or ethical principles.

In this paper we presented the full spectrum of DSEIs in dementia care as they are described in the available scientific literature (including medical and nursing journals, organised public consultations and surveys). Our review covers all DSEIs for dementia care that were presented in the already mentioned systematic review of the older literature published between 1980 and $2000 .^{7}$ In addition, our review revealed further DSEIs, further specified DSEIs and directly linked the DSEIs to the relevant references. The findings of this comprehensive and detailed review can raise the awareness that general ethical principles such as 'respect of patient autonomy' or 'beneficence' obviously need specification (see Appendix) to inform medical decision-making in all its different steps (for example information about the patient, assessing patient decision-making competence, evaluating former decisions and current practice).

\section{Categorisation of DSEIS}

This review is the first one that demonstrates what the categorisation and reporting of DSEIs can look like. Further evaluation is needed 
to assess the advantages and disadvantages of this structured and detailed reporting on DSEIs, in comparison with other more general and abstract types of reporting ${ }^{7}$ or narrative book-length descriptions. ${ }^{2,14}$ However, the detailed categorisation of DSEIs as the main finding of this review highlights a core challenge in applying systematic review methodology to the field of bioethics: the critical appraisal of systematic reviews of ethics literature should not only address the quality of the literature search but also, with equal importance, the validity and usefulness of the synthesis of findings. Thus, in this review, the full spectrum of DSEIs is presented in first- and second-order categories.

This DSEI spectrum can serve various purposes. It can be used as training material for healthcare professionals, students and the public, to raise awareness and improve understanding of the complexity of ethical issues in dementia care. It can also be used for the systematic and transparent identification of ethical issues that should be addressed in dementia-specific training programmes, national strategy plans and clinical practice guidelines.

We recommend employing the methods applied in this review for the systematic identification of DSEIs in other cognitive and somatic diseases. Although different first- and second-order categories are to be expected for ethical issues in other diseases we assume that the overarching structure of our DSEI spectrum is applicable to all diseases, namely six major categories that deal with the stepwise processes of medical decision-making and one additional major category dealing with specific care situations. Whereas the literature on DSEIs in dementia care was extensive, and therefore allowed theoretical saturation of the respective DSEI spectrum, systematic reviews of DSEIs in other diseases might retrieve fewer references that address DSEIs. To reach theoretical saturation of the respective DSEI spectrum in these cases the systematic literature review might need to be complemented by expert input on DSEIs or surveys of healthcare professionals, patients and relatives. Further research is needed on how these complementary DSEI sources can be integrated in an equally systematic and transparent manner.

\section{Limitations}

One limitation of this first systematic review of DSEIs might be seen in the fact that we restricted our search to Medline and Google books. It is clear to us that although our review was systematic we did not include 'all' the existing literature dealing with ethical issues in dementia care. We restricted our search to the above-mentioned databases for four main reasons: first, and most important, we reached theoretical saturation for the firstand second-order categories of DSEIs after assessing the 92 references retrieved for Medline and Google books. We did not aim to reach theoretical saturation for the third-order categories. Second, former systematic reviews in the field of bioethics demonstrated the broad coverage of ethics literature in Medline and the little additional value of searching medical ethics literature in other databases such as EMBASE, CINAHL or Euroethics. ${ }^{15,16}$ Third, the characteristics of publications included in this systematic review (Table 1) demonstrate that the 92 references covered journals from all relevant fields. Fourth, the 92 references included several narrative reviews, ${ }^{3,17}$ topic-specific monographs ${ }^{14,18}$ and comprehensive reports such as the Nuffield Council on Bioethics report on dementia. ${ }^{2}$ Currently, the field of systematic reviews on ethical issues (or argument-based literature in general) lacks broadly consented standards such as those available for systematic reviews on clinical research, for example Moher et al. ${ }^{19}$ Further conceptual and empirical research should address the question on how to modify systematic review methodology for its reasonable application in the field of bioethics. ${ }^{20-23}$
We stress the fact that a systematic and transparent process in identifying ethical issues does not automatically indicate that further steps in dealing with such a spectrum are systematic, too. Further research is needed to evaluate how health policy decision-makers or guideline-development panels can chose the 'most important or pressing' DSEI from the full spectrum in a transparent and participative manner. The purpose of this review was not to quantify how often certain DSEIs have been mentioned in the literature. It is questionable whether such frequency data are helpful. It might, however, be important to know whether a certain DSEI is more or less frequent in ordinary dementia care. However, such frequency data cannot be derived by counting how often a certain DSEI has been mentioned in the literature. Survey research among carers and patients, informed by the findings of this review, would be a better tool for gaining these frequency data. Further challenges in interpreting quantitative characteristics of systematic reviews in bioethics are described elsewhere. $^{20}$

\section{Ethical decision-making in dementia care}

It should be stated that the process of drafting recommendations on how to deal with individual DSEIs faces several methodological challenges. ${ }^{24}$ On the one hand, oversimplification needs to be avoided to guarantee meaningful and helpful content. The Nuffield Council report provides a good example of how some of the complex DSEIs captured in our DSEI spectrum can be addressed by providing a set of criteria that do not indicate a one-size-fits-all solution for ethical challenges but rather guide the process of ethical decision-making in dementia care. A good example is the second-order DSEI 'Problems concerning understanding and handling of patient autonomy'. The Nuffield Council addresses this DSEI as follows: 'Wellbeing factors, such as the person's general level of happiness are also important but again cannot automatically take precedence over the person's interests in having their autonomy respected.' ${ }^{2}$ In the following, the Nuffield Council suggests factors that should be taken into account when weighing up the conflicting ethical principles in dementia care (well-being $v$. respect of autonomy):

'(i) How important is the issue at stake?, (ii) How much distress or pleasure is it causing now?, (iii) Have the underlying values or beliefs on which the earlier preferences were based genuinely changed or can they be interpreted in a new light?, (iv) Do the apparent changes in preferences or values result from psychosocial factors (such as fear) or directly from the dementia (such as sexually disinhibited behaviour), or are they linked with a genuine pleasure in doing things differently?'2

Future developments of dementia-care-specific clinical guidelines, information material and national strategy plans can use the findings of this review for the identification and prioritisation of key ethical issues in dementia care. In addition, transparent procedures should be applied for drafting and approving recommendations that guide everyday ethical decision-making in dementia care.

Daniel Strech, MD, PhD, Hannover Medical School, Institute for History, Ethics and Philosophy in Medicine, Hannover, Germany, and Department of Biomedical Ethics, University of Zurich, Switzerland; Marcel Mertz, MA, Hannover Medical School, Institute for History, Ethics and Philosophy in Medicine, Hannover and University of Mannheim, Department of Philosophy, Mannheim; Hannes Knüppel, MPH, Gerald Neitzke, MD, Hannover Medical School, Institute for History, Ethics and Philosophy in Medicine, Hannover; Martina Schmidhuber, PhD, Hannover Medical School, Medicine, Hannover; Martina Schmidhuber, PhD, Hannover Medical School,
Institute for History, Ethics and Philosophy in Medicine, Hannover and University of Bielefeld, Department of Philosophy, Bielefeld, Germany

Correspondence: Daniel Strech, Hannover Medical School, Institute for History, Ethics and Philosophy in Medicine, CELLS - Centre for Ethics and Law in the Life Sciences, Carl-Neuberg Straße 1, 30625 Hanover, Germany. Email: strech.daniel@mh-hannover.de

First received 12 Jun 2012, final revision 10 Dec 2012, accepted 19 Dec 2012 


\section{Funding}

This work was funded by the German Research Foundation (DFG) (Project number: STR 1070/2-1).

\section{Acknowledgements}

The authors would like to thank Julian Hughes, Georg Marckmann and Reuben Thomas for critical feedback on an earlier version of this paper.

\section{Appendix}

\section{The spectrum of disease-specific ethical issues (DSEIs) in dementia care}

\section{Diagnosis and medical indication}

Adequate consideration of complexity of diagnosing dementia:

- Risk of making a diagnosis too early or too late because of reasons related to differences in age- or gender-related disease frequencies ${ }^{3,25}$

- Risk of making inappropriate diagnoses related to varying definitions of mild cognitive impairment $2,3,12,17,26-30$

- Underestimation of the relatives' experiences and assessments of the person with dementia $2,30,31$

Adequate point of making a diagnosis:

- Risk of disavowing signs of illness and disregarding advanced planning 3,12,31,32

- Respecting psychological burdens in breaking bad news ${ }^{17,30,31,33}$

- Underestimation of the relatives' experiences and assessments of the person with dementia $2,30,31$

Reasonableness of treatment indications:

- Overestimation of the effects of current pharmaceutical treatment options $^{27,34}$

- Considering challenges in balancing benefits and harms (sideeffects) $)^{2,3,34-36}$

- Not considering information from the patient's relatives ${ }^{2,5,18,37}$

Adequate appreciation of the patient:

- Insufficient consideration of the patient as a person 2,3,6,14,26,30,31,38-40

- Insufficient consideration of existing preferences of the patient ${ }^{2,3,14,17,31,34,35,40-50}$

- Problems concerning understanding and handling of patient autonomy ${ }^{2,3,12,40,51,52}$

2 Assessing patient decision-making competence

Ambiguity in understanding competence ${ }^{2,3,6,12,14,17,52-57}$

Problematic aspects in patient decision-making competence:

- Inadequate assessment $2,3,4,14,29,57,58$

- Inadequate consideration of setting or decision content $2,3,4,12,59$

- Disregarding the complexity of assessing authenticity 2,3,14,55,60,61

- Underestimation of the relatives' experiences and assessments of the patient ${ }^{2,30}$

3 Information and disclosure

- Respecting patient autonomy in the context of disclosure 2,3,6,12,35,53,57,59,62

- Adequate amount and manner of information 2,3,6,14,31,33,35,59,62

- Adequate involvement of relatives 2,4,33,59

- Consideration of cultural aspects 2,4

4 Decision-making and consent

Improvement of patient decision-making competence:

- Risk of inadequate involvement of the patient in the decision-making process $^{5,6,49,53}$

- Risk of insufficient conditions for fostering decision-making capacity ${ }^{2,3,12,63}$

- Risk of disregarding the need of continuous relationship building with the patient as a means to foster patient autonomy 2,3,6,53

- Risk of setting the time for decision-making processes too short ${ }^{2,3}$

- Risk of weakening patient decision-making competence by infantilisation ${ }^{2,31}$
Responsible surrogate decision-making:

- Adequate handling of 'best interest' and 'substituted judgements' decisions $^{2-4,6,12,14,17,35,40,51,52,55,64-71}$

- Inadequate communication with relatives $2,3,6,14,26,37,39,72-78$

- Inadequate handling of information stemming from relatives, 2,3,37,53,73,79

- Need of advanced planning ${ }^{2-6,12,48,75}$

- Risk of disregarding legal clarifications ${ }^{2,3,6}$

Adequate consideration of living wills/advance directives:

- Challenges in interpreting the living will/advance directive $3,6,41,53,60,66,70,80$

- Challenges in deciding to follow or not to follow the content of the living will/advance directive $2,4,14,35,53,66,67,70$

5 Social and context-dependent aspects

- Caring for relatives $2,3,4,6,14,18,30,31,76,77,81-83$

- Caring for clinical personnel and professional carers $2,13,77,84-87$

- Assessment of the patient's potential to do (direct or indirect) harm to others ${ }^{4,5,36,88}$

- Responsible handling of costs and allocation of limited resources 2,3,5,12,27,89

6 Care process and process evaluation

- Continuing assessment of potential benefits and harms 2,34-36,90

Adequate patient empowerment:

- Patient-oriented setting 2,5,6,30,37,91

- Motivation of patients $30,31,32,92$

Self-reflection of carers:

- Attitudes towards patients with dementia $2,5,90$

- Reflection on conflicts of interests and values $2,4,5,53,93,94$

- Continuing education/capacity building of the carers $2,4,31,84,95,96$

Evaluation of abuse and neglect $2,4,12$

\section{Special situations for decision-making}

Ability to drive $4-6,12,88,97$

Sexual relationships ${ }^{2,12}$

Indication for genetic testing 6,12

Usage of GPS (global positioning system) and other monitoring

techniques ${ }^{2,14,98-100}$

Prescription of antibiotics 36,68

Prescription of antipsychotic drugs 2,12

Indication for brain imaging 2,89

Covert medication ${ }^{14,101,102}$

Restraints $2,5,6,17,53,87,89,103,104$

Tube feeding $2,4-6,12,14,46,58,69,78,105-107$

End of life/palliative care ${ }^{2,6}$

Suicidality ${ }^{44,61}$

\section{References}

1 Post SG, Whitehouse PJ. Fairhill guidelines on ethics of the care of people with Alzheimer's disease: a clinical summary. Center for Biomedical Ethics, Case Western Reserve University and the Alzheimer's Association. J Am Geriatr SOC 1995; 43: 1423-9.

2 Nuffield Council on Bioethics. Dementia: Ethical Issues. Nuffield Council on Bioethics, 2009

3 Oppenheimer C. Ethics in old age psychiatry. In Psychiatric Ethics (eds S Bloch, S Green): 409-33. Oxford University Press, 2009.

4 Rabins PV, Black BS. Ethical issues in geriatric psychiatry. Int Rev Psychiatry 2010; 22: 267-73.

5 Rai GS, Eccles J. Ethical issues in dementia. In Medical Ethics and the Elderly (ed. G Rai): 125-37. Radcliffe, 2009.

6 Bernat JL. Ethical issues in the care of patients with dementia. In Handbook of Clinical Neurology (eds C Duyckaerts, I Litvan): 115-30. Elsevier, 2008.

7 Baldwin C, Hughes J, Hope T, Jacoby R, Ziebland S. Ethics and dementia: mapping the literature by bibliometric analysis. Int J Geriatr Psychiatry 2003; 18: $41-54$.

8 Hughes JC, Hope T, Savulescu J, Ziebland S. Carers, ethics and dementia: a survey and review of the literature. Int J Geriatr Psychiatry 2002; 17: 35-40.

9 Beauchamp TL, Childress JF. Principles of Biomedical Ethics. Oxford University Press, 2008.

10 ABIM Foundation, ACP-ASIM Foundation, European Federation of Internal Medicine. Medical professionalism in the new millennium: a physicians' charter. Lancet 2002; 359: 520-2. 
11 American Psychiatric Association. The Principles of Medical Ethics: With Annotations Especially Applicable to Psychiatry. APA, 2010.

12 Walaszek A. Clinical ethics issues in geriatric psychiatry. Psychiatr Clin North Am 2009; 32: 343-59.

13 Strauss A, Corbin JM. Basics of Qualitative Research: Techniques and Procedures for Developing Grounded Theory. Sage Publications, 1998.

14 Hughes JC, Baldwin C. Ethical Issues in Dementia Care: Making Difficult Decisions. Jessica Kingsley, 2006.

15 Sofaer N, Strech D. Reasons why post-trial access to trial drugs should, or need not be ensured to research participants: a systematic review. Public Health Ethics 2011; 4: 160-84.

16 Strech D, Persad G, Marckmann G, Danis M. Are physicians willing to ration health care? Conflicting findings in a systematic review of survey research Health Policy 2009; 90: 113-24.

17 Hughes JC, Baldwin C. Ethics and the old age psychiatry. In Oxford Textbook of Old Age Psychiatry (eds R Jacoby, C Oppenheimer, T Dening): 709-29. Oxford University Press, 2008.

18 Wetzstein V. Diagnose Alzheimer: Grundlagen einer Ethik der Demenz [Diagnosing Alzheimer's Disease: Fundamentals of Dementia Ethics]. Campus Verlag, 2005.

19 Moher D, Liberati A, Tetzlaff J, Altman DG. Preferred reporting items for systematic reviews and meta-analyses: the PRISMA statement. Ann Intern Med 2009; 151: 264-9, W64.

20 Strech D, Sofaer N. How to write a systematic review of reasons. J Med Ethics 2012; 38: 121-6.

21 Sofaer N, Strech D. The need for systematic reviews of reasons. Bioethics 2012; 26: 315-28.

22 Strech D, Synofzik M, Marckmann G. Systematic reviews of empirical bioethics. Conceptual challenges and practical recommendations. J Med Ethics 2008; 34: 472-7.

23 McCullough LB, Coverdale JH, Chervenak FA. Constructing a systematic review for argument-based clinical ethics literature: the example of concealed medications. J Med Philos 2007; 32: 65-76.

24 Eriksson S, Hoglund AT, Helgesson G. Do ethical guidelines give guidance? A critical examination of eight ethics regulations. Camb Q Healthc Ethics 2008; 17: 15-29.

25 Schmidt R. Geschlechtsspezifische unterschiede der Alzheimer demenz [Gender-specific differences of Alzheimer's disease]. Neuropsychiatr 2008; 22: 1-15.

26 Murray LM, Boyd S. Protecting personhood and achieving quality of life for older adults with dementia in the U.S. health care system. $J$ Aging Health 2009; 21: 350-73.

27 Graham JE, Ritchie K. Mild cognitive impairment: ethical considerations for nosological flexibility in human kinds. Philos Psychiatr Psychol 2006; 13: $31-43$.

28 Diehl J, Fröstl H, Kurz A. Alzheimer-krankheit. Symptomatik, diagnose und therapie [Alzheimer's disease. Symptoms, diagnosis and therapy]. Z Med Ethik 2005; 51: 3-12.

29 Helmchen H, Lauter H. Dürfen Ärzte mit Demenzkranken Forschen? Forschungsbedraf und Einwiliigungsproblematik bei Demenz [Should Physicians Conduct Research with Dementia Patients? Research Needs and Consent Challenges in Dementia]. Thieme, 1995.

30 Füsgen I. Demenz. Praktischer Umgang mit der Hirnleistungsstörung [Dementia: A Practice Guide for the Brain Disorder]. MMV Medizin Verlag, 1995.

31 Steeman E, de Casterlé BD, Godderis J, Grypdonck M. Living with early-stage dementia: a review of qualitative studies. J Adv Nurs 2006; 54: 722-38.

32 Kruse A. Lebensqualität demenzkranker menschen [Quality of life in people with dementia]. Z Med Ethik 2005; 51: 41-57.

33 Carpenter B, Dave J. Disclosing a dementia diagnosis: a review of opinion and practice, and a proposed research agenda. Gerontologist 2004; 44 $149-58$

34 Synofzik M. Effective, indicated-and yet without benefit? The goals of dementia drug treatment and the well-being of the patient [in German]. Z Gerontol Geriatr 2006; 39: 301-7.

35 Briggs S, Vernon M. Informed consent. In Medical Ethics and the Elderly (ed. G Rai): 19-29. Radcliffe, 2009

36 Schwaber MJ, Carmeli Y. Antibiotic therapy in the demented elderly population: redefining the ethical dilemma. Arch Intern Med 2008; 168 : 349-50.

37 Oliver D, Gee P. Communication, barriers to it and information sharing In Medical Ethics and the Elderly (ed. G Rai): 49-61. Radcliffe, 2009.
38 Post SG. Respectare: moral respect for the lives of the deeply forgetful. In Dementia: Mind, Meaning and the Person (eds JC Hughes, S Louw SR Sabat): 223-34. Oxford University Press, 2006.

39 Penrod J, Yu F, Kolanowski A, Fick DM, Loeb SJ, Hupcey JE. Reframing person-centered nursing care for persons with dementia. Res Theory Nurs Pract 2007; 21: 57-72.

40 Mahon MM, Sorrell JM. Palliative care for people with Alzheimer's diesease. Nurs Philos 2008; 9: 110-20.

41 Hughes JC, Sabat SR. The advance directive conjuring trick and the person with dementia. In Empirical Ethics in Psychiatry (eds G Widdershoven, J McMillan, T Hope): 123-40. Oxford University Press, 2008

42 Bouman W. Sexuality in later life. In Oxford Textbook of Old Age Psychiatry (eds R Jacoby, C Oppenheimer, T Dening, A Thomas): 689-707. Oxford University Press, 2008.

43 Bavidge M. Aging and human nature. In Dementia: Mind, Meaning, and the Person (ed. JC Hughes): 41-53. Oxford University Press, 2006.

44 Rabins PV. Can suicide be a rational and ethical act in persons with early or pre-dementia? Am J Bioeth 2007; 7: 47-9.

45 Bowling A. Quality of life in healthcare decisions. In Medical Ethics and the Elderly (ed. G Rai): 149-56. Radcliffe, 2009.

46 Gove E, Sparr S, Dos Santos Bernardo AM, Cosgrave MP, Jansen S, Martensson B, et al. Recommendations on end-of-life care for people with dementia. J Nutr Health Aging 2010; 14: 136-9.

47 Jones WJ, McCullough LB, Richman BW. Advanced age, dementia, and an abdominal aneurysm: intervene? J Vasc Surg 2003; 37: 1132-3.

48 Baumrucker SJ, Davis MP, Paganini E, Morris GM, Stolick M, Sheldon JE. Case study: dementia, quality of life, and appropriate treatment. Am J Hosp Palliat Care 2005; 22: 385-91.

49 Menne $\mathrm{HL}$, Whitlatch $\mathrm{CJ}$. Decision-making involvement of individuals with dementia. Gerontologist 2007; 47: 810-9.

50 Weissenberger-Leduc M. Palliativpflege bei Demenz [Palliative Care in Dementia]. Springer, 2009.

51 Boyle G. Social policy for people with dementia in England: promoting human rights. Health Soc Care Community 2010; 18: 511-9.

52 Dworkin R. Autonomy and the demented self. In An Anthology of Psychiatric Ethics (eds S Green, S Bloch): 293-6. Oxford University Press, 2006.

53 Defanti CA, Tiezzi A, Gasparini M, Congedo M, Tiraboschi P, Tarquini D, et al. Ethical questions in the treatment of subjects with dementia. Part I. Respecting autonomy: awareness, competence and behavioural disorders. Neurol Sci 2007; 28: 216-31.

54 Luttrell S. Mental capacity and best interests. In Medical Ethics and the Elderly (ed. G Rai): 71-9. Radcliffe, 2009.

55 Holm S. Autonomy, authenticity, or best interest: everyday decision-making and persons with dementia. Med Health Care Philos 2001; 4: 153-9.

56 Jaworka A. Respecting the marking of agency. Philos Public Aff 1999; 28: 105-38.

57 Welie S. Patient incompetence in the practice of old age psychiatry: the significance of empirical research for the law. In Empirical Ethics in Psychiatry (ed. G Widdershoven): 231-47. Oxford University Press, 2008.

58 Chernoff R. Tube feeding patients with dementia. Nutr Clin Pract 2006; 21 $142-6$.

59 Cornett PF, Hall JR. Issues in disclosing a diagnosis of dementia. Arch Clin Neuropsychol 2008; 23: 251-6.

60 Vollmann J. Advance directives in patients with Alzheimer's disease. Ethical and clinical considerations. Med Health Care Philos 2001; 4: 161-7.

61 Hartmann J, Förstl H, Kurz A. Suizid bei beginnender Demenz [Suicide in early-stage dementia]. Z Med Ethik 2009; 55: 343-50.

62 Schermer M. Nothing but the truth? On truth and deception in dementia care. Bioethics 2007; 21: 13-22.

63 Hofmann S. Demenz und Autonomie: Zur Realtionalität des Autonomiebegriffs in der Pflege bei Menschen mit Demenz [Dementia and Autonomy: The Challenge of the Concept of Autonomy in the Care of People with Dementia]. VDM, 2010.

64 Dworkin R. Life's Dominion: An Argument about Abortion, Euthanasia, and Individual Freedom. Knopf, 1993.

65 Dresser R. Dworkin on Dementia. In An Anthology of Psychiatric Ethics (eds S Green, S Bloch): 297-301. Oxford University Press, 2006.

66 Maio G. Verfügen über das Unverfügbare? Die Patientenverfügung als unvollkommene Antwort auf die ethische Herausforderung des Sterbens [Controlling the uncontrollable? The advance directive as the imperfect answer to the ethical challenge of dying]. Jahrb Wiss Ethik 2010; 15: 211-20.

67 Harvey M. Advance directives and the severely demented. J Med Philos 2006; 31: $47-64$. 
68 Rozzini R, Trabucchi M. Antibiotic therapy in elderly persons affected by severe dementia. Arch Intern Med 2008; 168: 2497-8.

69 Geppert CM, Andrews MR, Druyan ME. Ethical issues in artificial nutrition and hydration: a review. JPEN J Parenter Enteral Nutr 2010; 34: 79-88.

70 Gastmans C, Denier $Y$. What if patients with dementia use decision aids to make an advance euthanasia request? Am J Bioeth 2010; 10: 25-6.

71 Gedge EB. Collective moral imagination: making decisions for persons with dementia. J Med Philos 2004; 29: 435-50.

72 Goldsteen M. Empirical ethics in action in practices of dementia care. In Empirical Ethics in Psychiatry (eds G Widdershoven, J McMillan, T Hope): 95-106. Oxford University Press, 2008.

73 Barnes M, Brannelly T. Achieving care and social justice for people with dementia. Nurs Ethics 2008; 15: 384-95.

74 Kaldjian LC, Shinkunas LA, Bern-Klug M, Schultz SK. Dementia, goals of care and personhood: a study of surrogate decision makers' beliefs and values. Am J Hosp Palliat Care 2010; 27: 387-97.

75 Kwok T, Twinn S, Yan E. The attitudes of Chinese family caregivers of olde people with dementia towards life sustaining treatments. J Adv Nurs 2007; 58: $256-62$.

76 Baldwin C. Family carers, ethics and dementia: an empirical study. In Empirical Ethics in Psychiatry (eds G Widdershoven, J McMillan, T Hope): 107-21. Oxford University Press, 2008.

77 Bolmsjo IA, Edberg AK, Sandman L. Everyday ethical problems in dementia care: a teleological model. Nurs Ethics 2006; 13: 340-59.

78 Synofzik M. Tube-feeding in advanced dementia. An evidence-based ethical analysis [in German]. Nervenarzt 2007; 78: 418-28.

79 Nagao N, Aulisio MP, Nukaga Y, Fujita M, Kosugi S, Youngner S, et al. Clinica ethics consultation: examining how American and Japanese experts analyze an Alzheimer's case. BMC Med Ethics 2008; 9: 2.

80 Schermer M. In search of 'good life' for demented elderly. Med Health Care Philos 2003; 6: 35-44.

81 Kastner U, Löbach R. Handbuch Demenz [The Dementia Handbook]. Urban \& Fischer, 2007

82 Lawrence V, Murray J, Samsi K, Banerjee S. Attitudes and support needs of Black Caribbean, south Asian and White British carers of people with dementia in the UK. Br J Psychiatry 2008; 193: 240-6.

83 Gatterer G, Croy A. Leben mit Demenz: Praxisbezogener Ratgeber für Pflege und Betreuung [Living with Dementia: Practice Guide for Care and Support] Springer, 2004.

84 Jakobsen $\mathrm{R}$, Sorlie V. Dignity of older people in a nursing home: narratives of care providers. Nurs Ethics 2010; 17: 289-300

85 Cohen-Mansfield J, Bester A. Flexibility as a management principle in dementia care: the Adards example. Gerontologist 2006; 46: 540-4.

86 Reitinger E, Pleschberger S, Schumann F. Living and dying in community based housing for people with dementia. An exploratory qualitative study [in German]. Z Gerontol Geriatr 2010; 43: 285-90.

87 Yamamoto M, Aso Y. Placing physical restraints on older people with dementia. Nurs Ethics 2009; 16: 192-202.

88 Robinson D, O'Neill D. Ethics of driving assessment in dementia: care, competence and communication. In Medical Ethics and the Elderly (ed. G Rai): 101-9. Radcliffe, 2009.
89 Rosen AC, Bokde AL, Pearl A, Yesavage JA. Ethical, and practical issues in applying functional imaging to the clinical management of Alzheimer's disease. Brain Cogn 2002; 50: 498-519.

90 Kalis A, von Delden J, Schermer M. 'The good life' for demented persons living in nursing homes. Int Psychogeriatr 2004; 16: 429-39.

91 Villars H, Oustric S, Andrieu S, Baeyens JP, Bernabei R, Brodaty H, et al. The primary care physician and alzheimer's disease: an international position paper. J Nutr Health Aging 2010; 14: 110-20.

92 Sabat S. Subjectivity, the brain, life narratives and the ethical treatment of persons with Alzheimer's disease. Am J Bioeth 2009; 9: 23-5.

93 Morris C. Personal construct psychology and person-centred care. In CareGiving in Dementia: Research and Applications (Vol 3) (eds GMM Jones, BL Miesen): 67-94. Brunner-Routledge, 2004.

94 Kalis A, van Delden J, Schermer M. Ideals regarding a good life for nursing home residents with dementia: views of professional caregivers. Nurs Ethics 2005; 12: 30-42.

95 Hughes J. Dementia and ethics: the view of informal carers. J $R$ Soc Med 2002; 95: 242-6.

96 Richter J, Eisemann MR. Attitudinal patterns determining decision making in the treatment of the elderly: a comparison of the physicians and the nurses in Germany and Sweden. Intensive Care Med 2000; 26: 1326-33.

97 Rapoport MJ, Herrmann N, Molnar FJ, Man-Son-Hing M, Marshall SC, Shulman $\mathrm{K}$, et al. Sharing the responsibility for assessing the risk of the driver with dementia. CMAJ 2007; 177: 599-601.

98 Landau R, Auslander GK, Werner S, Shoval N, Heinek J. Families' and professional caregivers' views of using advanced technology to track people with dementia. Qual Health Res 2010; 20: 409-19.

99 Kang HG. In situ monitoring of health in older adults: technologies and issues. J Am Geriatr Soc 2010; 58: 1579-86.

100 Landau R, Auslander GK, Werner S, Shoval N, Heinik J. Who should make the decision on the use of GPS for people with dementia? Aging Ment Health 2011; 15: 78-84.

101 Hokanen L. Point-counterpoint: is it ethical to give drugs covertly to people with dementia? No: covert medication is paternalistic. West J Med 2001; 174: 229.

102 Lamnari A. Point-counterpoint: is it ethical to give drugs to people with dementia? Yes: it is ethical if it is in their best interests. West J Med 2001; 174: 228.

103 Sayers GM, Rai G. The lawful use of restraints. In Medical Ethics and the Elderly (ed. G Rai): 139-47. Radcliffe, 2009.

104 Weiner C, Tabak N, Bergman R. The use of physical restraints for patients suffering from dementia. Nurs Ethics 2003; 10: 512-25.

105 Briggs S, Vernon M. Decisions on life-sustaining therapy: nutrition and fluid. In Medical Ethics and the Elderly (ed. G Rai): 31-46. Radcliffe, 2009.

106 Venturo L. Dignity, dining and dialogue: reviewing the literature on quality of life. Int J Older People Nurs 2010; 5: 228-34.

107 Werner S. Über Essen und Trinken demenziell erkrankter Bewohner: "Marmeladenstullen und Pdding am Abend? ..." [About food and drink of dementia residents: 'Jam sandwiches and pudding in the evening?']. Pflegezeitschrift 2010; 63: 78-80. 